\title{
Determining the relationship between early postmortem loin quality attributes and aged loin quality attributes using meta-analyses techniques ${ }^{1}$
}

\author{
Bailey N. Harsh, ${ }^{\dagger, 2}$ Dustin D. Boler, ${ }^{1}$ Steven D. Shackelford, ${ }^{\ddagger}$ and Anna C. Dilger ${ }^{\dagger, 3}$ \\ Department of Animal Sciences, University of Illinois, Urbana-Champaign, IL 6180 and United States \\ Department of Agriculture, ARS, U.S. Meat Animal Research Center, Clay Center, NE 68933
}

\begin{abstract}
Meta-analyses techniques using 11 independent datasets were used to determine correlations between pork loin quality evaluated at 1-d postmortem and quality evaluated at 12- to 28-d postmortem. Datasets encompassed approximately 3,957 loins. The effects of aging on ventral loin surface quality were determined using a paired-T test. Ventral loin surfaces become $8 \%$ lighter $(P<0.0001), 44.5 \%$ redder $(P<0.0001)$, and $46 \%$ more yellow $(P<0.0001)$ during the aging period. Therefore, it is apparent that loin quality changes during postmortem aging. Because of this, it becomes necessary to determine the correlation between early and aged pork quality parameters. Pearson correlation coefficients within original datasets were calculated, and then sample-weighted mean correlations $(\bar{r})$ and variances $[\operatorname{Var}(\mathrm{r})]$ were calculated across datasets. Early postmortem ventral instrumental lightness $\left(\mathrm{L}^{*}\right)$ was moderately correlated with aged ventral $\mathrm{L}^{*}(\bar{r}=0.50)$, aged ventral visual color $(\bar{r}=-0.38)$, aged chop face (freshly cut) $\mathrm{L}^{*}(\bar{r}=0.44)$, and aged chop face visual color $(\bar{r}=-0.38)$. Early postmortem ventral instrumental redness $\left(\mathrm{a}^{*}\right)$ was moderately correlated with aged ventral a* $(\bar{r}=0.49)$ and aged
\end{abstract}

chop face $a^{*}(\bar{r}=0.46)$. Early postmortem ventral visual color was moderately correlated with aged ventral $\mathrm{L}^{*}(\bar{r}=-0.51)$, aged ventral color $(\bar{r}=0.50)$, aged chop face $\mathrm{L}^{*}(\bar{r}=-0.43)$, and aged chop face visual color $(\bar{r}=0.43)$. However, no instrumental or visual color parameters were moderately or strongly correlated with instrumental tenderness or sensory panel ratings of tenderness and juiciness $(|\bar{r}| \leq 0.36)$. Early postmortem ventral visual marbling was moderately correlated with aged ventral marbling $(\bar{r}=0.63)$ and aged chop face visual marbling $(\bar{r}=0.56)$. Visual marbling was not $(|\bar{r}| \leq 0.12)$ correlated with instrumental tenderness or sensory panel ratings of tenderness and juiciness. Stepwise regression, using a holo-analysis approach, was used to determine the predictive ability of early postmortem ventral color, marbling, firmness, and $\mathrm{pH}$ on sensory panels ratings of tenderness $\left(R^{2}=0.13\right)$, juiciness $\left(R^{2}=0.09\right)$, and flavor $\left(R^{2}=0.28\right)$. Early postmortem color and marbling are important pork quality traits in consumers purchasing decisions, but are poorly related to traits associated with eating experience. Still, they may be predicative of traits associated with purchasing intent.

Key words: correlation, holo-analysis, meta-analysis, pork, quality, sensory

(C) The Author(s) 2018. Published by Oxford University Press on behalf of the American Society of Animal Science. All rights reserved. For permissions, please e-mail: journals.permissions@oup.com.

J. Anim. Sci. 2018.96:3161-3172 doi: 10.1093/jas/sky183

\footnotetext{
${ }^{1}$ Funding, wholly or in part, was provided by The National Pork Board. Mention of trade names, proprietary products, or specified equipment does not constitute a guarantee or warranty by the United States Department of Agriculture (USDA) and does not imply approval to the exclusion of other products that may be suitable. The USDA is an equal opportunity provider and employer.
} 


\section{INTRODUCTION}

Predicting and improving quality is an important goal for the pork industry. The adoption of a U.S. pork quality grading system, based on early postmortem visual color and marbling, has been proposed as a potential strategy to improve pork quality (USDA, 2017). Previously, consumers rated darker-colored pork chops as juicier than lighter-colored pork chops (Norman et al., 2003), and darker color and greater marbling were positively correlated with sensory panel ratings of tenderness of pork loins (Huff-Lonergan et al., 2002). A challenge with the proposed grading system is that, commercially, loins are evaluated on the ventral surface of the loin at 1-d postmortem, but consumers use the transverse section (chop face) of the loin after a period of aging to make purchasing decisions and determine eating experience. For a pork quality grading system to be successful, quality estimates determined at the production facility on the ventral surface of the loin (1-d postmortem) must be correlated with aged quality estimates determined on the chop face and sensory characteristics. Although factors like the evaluation of quality attributes during fabrication have been addressed, what is less understood is the correlation between quality attributes measured at the time of grading and quality traits observed by the consumer after aging. Therefore, the objective was to calculate those correlations using meta-analyses techniques. A meta-analysis provides a quantitative, statistical approach to the summarization of previous literature and scientific findings and is a review of the literature, both published and unpublished, using a structured statistical approach (Schmidt and Hunter, 2014). By compiling results of multiple studies, statistical power is increased enabling greater precision in determining true relationships (Sauvant et al., 2008).

\section{MATERIALS AND METHODS}

\section{Study Selection Criteria}

Eleven independent experiments were selected for inclusion in the analysis. Inclusion criteria included studies where pigs were slaughtered at a commercial facility, loins were evaluated on the ventral surface of the loins on day-1 postmortem and then again after an aging period that ranged from 12 to $28 \mathrm{~d}$. More importantly, exclusion criteria for studies in the meta-analyses were those where pigs were raised or slaughtered in academic settings and where the pigs used in studies were considered no longer contemporaries to current U.S. pigs (i.e., historical studies were excluded). Using these specific predefined inclusion and exclusion criteria allows for appropriate industry application of the results. Original experimental objectives of the parent studies were not considered and often times multiple treatments (e.g., dietary, genotype, or slaughter day) were represented within a dataset. Data from published and unpublished experiments were used in the analysis because a meta-analysis is a review of all available information that meet the selection criteria, and are based on a structured statistical approach (Schmidt and Hunter, 2014).

\section{Independent Variables}

Eight independent variables were identified as potential indicators of aged quality and sensory traits. All independent variables were traits that could be measured at a processing facility in real time using noninvasive methods (methodology that would not decrease the total value of the loin). All 8 variables were measured on the ventral surface of the loin and included instrumental lightness $\left(\mathrm{L}^{*}\right)$, redness $\left(\mathrm{a}^{*}\right)$, yellowness $\left(b^{*}\right)$, visual color, visual marbling, subjective firmness, and early postmortem ultimate $\mathrm{pH}$ ( $>16-\mathrm{h}$ post exsanguination). Extractable lipid, of a pork chop trimmed of subcutaneous fat, was also included as an independent variable because extractable lipid should not change during postmortem aging. However, the visual detection of marbling may be influenced by things such as lighting or temperature of the loin (AMSA, 2012). Using extractable lipid as an independent variable provided an objective measurement for marbling.

Instrumental color values were measured with either a Konica Minolta colorimeter (Minolta Camera Company, Osaka, Japan) or a HunterLab Miniscan spectrophotometer (HunterLab Associates, Reston, VA) and used either D65 (noon daylight, $6500 \mathrm{~K}$ ) or $\mathrm{C}$ (average north sky daylight, $6774 \mathrm{~K}$ ) illuminant (AMSA, 2012). Because the objective of the analysis was to determine the correlation between early and postmortem loin quality traits and because correlations are unitless, data from both machines and both illuminants were pooled. Oxygenation of myoglobin was not controlled and likely differed among studies. However, all data were collected as dictated by the constraints of fresh pork data collection at a processing facility.

Visual color and marbling used the National Pork Producers Council standards for evaluation of fresh pork loins (NPPC, 1999). Likewise, subjective firmness scores were determined using the 
National Pork Producers Council standards for firmness (NPPC, 1991).

Extractable lipid data were collected on chops trimmed of all subcutaneous fat and accessory muscles. Lipid was then extracted using petroleum ether or a mixture of chloroform and methanol.

\section{Statistical Analyses}

There were 3 underlying objectives. Those were as follows: 1) evaluate the change in pork quality parameters during postmortem aging using a paired-T analysis; 2) correlate early postmortem loin quality parameters (color, marbling, firmness, and muscle $\mathrm{pH}$ ), with aged loin quality parameters; and 3) determine the predictive ability of early postmortem loin quality parameters for traits associated with purchasing intent (aged color and marbling) and eating experience (sensory tenderness, juiciness, and flavor with a holo-analysis.

Paired T-test. Individual loin served as the experimental unit for determination of changes in quality estimates between early and aged traits. Differences in early and aged loin quality variables within a loin were compared using the paired option of the PROC T-Test in SAS. Means was accepted as statistically different at $P \leq 0.05$.

Meta-analysis. Data from original datasets (experiments) were previously analyzed based on the objectives of the respective original experiment. Therefore, each dataset was first independently analyzed to determine the correlations between 8 independent variables (early postmortem traits) and 17 dependent variables (aged postmortem traits). Pearson correlation coefficients for original datasets were calculated using the CORR procedure of SAS. A dataset consisting of the study name, number of observations, and the correlation coefficient was generated for each of the 136 combinations of independent and dependent variables. Then, the sample-weighted mean correlation $(\bar{r})$ and sample-weighted variance [Var(r)] were calculated such that studies with larger samples sizes were given more weight than studies with smaller sample sizes. These 2 statistics are sample-weighted because studies with a greater number of observations have less sample error than studies with fewer observations, and thus should be assigned more weight. The sample-weighted mean correlation was calculated using the following equation: $\bar{r}=\frac{\sum\left(N_{i} \times r_{i}\right)}{\sum N_{i}}$, where $N_{i}$ is the sample size for each study and $r_{i}$ is the observed correlation coefficient. Sample-weighted variance was calculated using the following equation: $(r)=\frac{\sum\left(N_{i} \times\left(r_{i}-\bar{r}\right)^{2}\right)}{\sum N_{i}}$.

Because the greatest source of variability across

original studies is sampling error (Arthur et al., 2001), the next step in the process was calculating sampling error variance. The effect of sampling error is that study coefficients will vary randomly from the population value. The meta-analysis procedures remove the variability across study coefficients that can be attributed to sampling error. This, in turn, results in a more accurate estimate of the true variance across the observed study coefficients. Sampling error variance was calculated using the following equation: $\operatorname{Var}(e)=\frac{\left(1-\bar{r}^{2}\right)^{2}}{(\bar{N}-1)}$, where $\bar{r}$ is the sample-weighted mean correlation and $\bar{N}$ is the average sample size of the original studies. From there, 95\% confidence intervals were calculated based on the sample-weighted mean correlation (rho). Lower confidence limits were calculated as follows: $\bar{r}-\left(1.96 \times\left(\frac{1-\left(\bar{r}^{2}\right)}{\sqrt{N-K}}\right)\right)$, where $N$ equals the total number of observations across all

studies and $K$ equals the number of studies included in the meta-analysis. Upper confidence limits were calculated as follows: $\bar{r}+\left(1.96 \times\left(\frac{1-\left(\bar{r}^{2}\right)}{\sqrt{N-K}}\right)\right)$. Sample-weighted mean correlations were considered different from zero when the 95\% confidence interval did not include zero. Correlations were considered low/weak when $|\bar{r}| \leq 0.35$, moderately correlated when $|\bar{r}|=0.36$ to 0.67 , and strongly correlated when $|\bar{r}|=0.68$ to 1.0 , similar to Taylor (1990).

Holo-analysis. Unlike a meta-analysis that requires qualification for data to be included in the analysis, a holo-analysis is defined as the integration of all available data on a specific topic (Rosen, 2006). Therefore, entire raw datasets rather than means from analyzed datasets were used to conduct a holo-analysis of the ability of noninvasive early postmortem loin quality traits (e.g., visual color, visual marbling, subjective firmness, and $\mathrm{pH}$ ) 
collected on the ventral surface of the loin to predict traits associated with purchasing intent and eating experience. Because variables such as instrument selection, illuminant selection, degree of observer selection, and machine aperture size are all known to influence instrumental color, CIE lightness $\left(L^{*}\right)$, redness $\left(a^{*}\right)$, and yellowness $\left(b^{*}\right)$ were not included in the list of predictor (independent variables). Likewise, because slice shear force and Warner-Bratzler shear force estimate tenderness in different magnitudes, instrumental tenderness was not included in the list of dependent variables. Data were analyzed using the REG procedure in SAS. Dependent variables included sensory tenderness, juiciness, flavor, and visual color and marbling of the cut surface of aged pork chops. Independent variables included visual color, visual marbling, and subjective firmness on the ventral surface of a 1-day postmortem boneless pork loin. Also included were $\mathrm{pH}$ and extractable lipid. Extractable lipid was included in the list of independent variables because intramuscular lipid should not change during aging. However, the ability to assess visual marbling is largely a function of the skill level of the technician. Extractable lipid provided a quantifiable measure of marbling. A linear regression equation was developed using the independent candidate variables to predict all dependent variables. The initial regression model included each of the 5 independent variables. Multicollinearity among independent variables was assessed using a variance inflation factor (VIF) statistic. However, no parameters exceeded VIF values of 2; therefore, all independent variables remained as candidate variables for selection in the model. Influence of individual observations on the estimated dependent variable was determined using the difference of fit (DFITTS) statistic. Observations were considered to have excessive influence on the estimation of the regression parameters when DFITTS $\geq 2\left[(p / n)^{1 / 2}\right]$, where $p$ was the number of parameters considered and $n$ is the total number of observations. Using the stepwise selection method, independent variables were required to have a significant $F$ statistic at the SLENTRY and SLSTAY level $=0.15$ to be included and remain in the final model.

\section{RESULTS}

\section{Changes in Pork Loin Quality During Aging}

Using T-tests to determine the differences between early and aged postmortem traits of the same loin allows for an estimate of the magnitudes of the changes expected in these traits with aging. Because of the very large sample size $(>3,950)$ used in this analysis, this T-test indicates statistical differences $(P<0.05)$ even with very small differences between early and aged quality estimates. Therefore, the magnitude of these changes is likely more useful for interpretation than the statement of statistical significance.

Ventral loin surfaces become $8 \%$ lighter $(P<0.0001), 44.5 \%$ redder $(P<0.0001)$, and $46 \%$ more yellow $(P<0.0001)$ during the aging period (Table 1). Instrumental lightness changed from 47.55 at 1 -day postmortem to 51.53 after the aging

Table 1. Comparison of early postmortem (1 d) ventral loin quality traits with aged (12 to $28 \mathrm{~d})$ postmortem ventral loin quality traits of whole boneless pork loins ${ }^{1}$

\begin{tabular}{|c|c|c|c|c|c|c|}
\hline \multirow[b]{2}{*}{ Item } & \multirow[b]{2}{*}{ Loins, $n$} & \multicolumn{2}{|c|}{ Days postmortem } & \multirow[b]{2}{*}{ Difference } & \multirow[b]{2}{*}{$\mathrm{SED}^{2}$} & \multirow[b]{2}{*}{$P$-value } \\
\hline & & Early & Aged & & & \\
\hline Lightness $^{3}, \mathrm{~L}^{*}$ & 3956 & 47.55 & 51.53 & -3.99 & 0.05 & $<0.0001$ \\
\hline Redness $^{4}, a^{*}$ & 3957 & 6.51 & 10.24 & -3.72 & 0.05 & $<0.0001$ \\
\hline Yellowness ${ }^{5}, b^{*}$ & 3957 & 4.78 & 7.64 & -2.86 & 2.41 & $<0.0001$ \\
\hline Visual color ${ }^{6}$ & 4259 & 2.9 & 3.1 & -0.2 & 0.01 & $<0.0001$ \\
\hline Visual marbling ${ }^{7}$ & 4253 & 2.4 & 2.0 & 0.4 & 0.01 & $<0.0001$ \\
\hline Subjective firmness ${ }^{8}$ & 4257 & 2.9 & 2.6 & 0.3 & 0.01 & $<0.0001$ \\
\hline
\end{tabular}

${ }^{1}$ Early and aged postmortem quality data are compared using a paired-T test on the same loin.

${ }^{2}$ Standard error of the difference of the mean.

${ }^{3} \mathrm{~L} *$ measures darkness to lightness (greater $\mathrm{L} *$ indicates a lighter color).

${ }^{4} \mathrm{a}^{*}$ measures redness (greater $\mathrm{a} *$ indicates a redder color).

${ }^{5} \mathrm{~b}^{*}$ measures yellowness (greater $\mathrm{b} *$ indicates a more yellow color).

${ }^{6} \mathrm{NPPC}$ color based on the 1999 standards measured in half point increments where $1=$ palest, $6=$ darkest.

${ }^{7}$ NPPC marbling based on the 1999 standards measured in half point increments where $1=$ least amount of marbling, $6=$ greatest amount of marbling.

${ }^{8}$ NPPC firmness based on the 1991 scale measured in half point increments where $1=$ softest, $5=$ firmest. 
period. Instrumental redness changed from 6.51 at 1-day postmortem to 10.24 after the aging period. Instrumental yellowness changed from 4.78 at 1-day postmortem to 7.64 after the aging period. Visual color also changed during the aging period, but the magnitude of the change was only 0.21 units $(P<0.0001)$. Therefore, it is apparent that color of the ventral surface changes during the postmortem aging period. although the differences represent a substantial change from an instrumental perspective, the visual change in color will likely not influence consumer purchasing decisions as consumers likely will not perceive this small difference. Likewise, early and aged estimates of visual marbling and subjective firmness scores were statistically different $(P<0.0001)$, but each changed less than a half of one respective NPPC unit.

\section{Correlations Between Early and Aged Loin Quality}

Color. Early postmortem ventral instrumental lightness $\left(\mathrm{L}^{*}\right)$ was moderately correlated with aged ventral lightness $(\bar{r}=0.50)$, aged ventral subjective color $(\bar{r}=-0.38)$, aged instrumental lightness of the chop face $(\bar{r}=0.44)$, and aged subjective color $(\bar{r}=-0.38)$ of the chop face (Table 2$)$. Early postmortem ventral instrumental lightness was not strongly correlated $(|\bar{r}| \geq 0.68)$ with any instrumental color or subjective color, marbling or firmness trait on the aged ventral surface of the loin or the aged but freshly cut chop face.

Early postmortem ventral instrumental redness $\left(a^{*}\right)$ was moderately correlated with aged ventral redness $(\bar{r}=0.49)$ and aged instrumental redness of the chop face $(\bar{r}=0.46$, Table 3$)$. Early postmortem ventral instrumental redness was not strongly correlated $(|\bar{r}| \geq 0.68)$ with any instrumental color or subjective color, marbling or firmness trait on the aged ventral surface of the loin or the aged but freshly cut chop face.

Early postmortem ventral instrumental yellowness $\left(b^{*}\right)$ was moderately correlated $(\bar{r}=0.37)$ with aged ventral lightness (Table 4$)$. Early postmortem ventral instrumental yellowness was not strongly correlated $(|(\bar{r})| \geq 0.68)$ with any instrumental color or subjective color, marbling or firmness trait on the aged ventral surface of the loin or the aged but freshly cut chop face.

Early postmortem ventral visual color was moderately correlated with aged ventral lightness $(\bar{r}=-0.51)$, aged ventral visual color $(\bar{r}=0.50)$, aged instrumental lightness of the chop face $(\bar{r}=-0.43)$, and aged subjective color $(\bar{r}=0.43)$ of the chop face (Table 5). Early postmortem

Table 2. Sample-weighted mean correlation coefficients of early (1 d) postmortem ventral loin surface instrumental lightness $\left(\mathrm{L}^{*}\right)$ values with aged loin and chop quality parameters

\begin{tabular}{|c|c|c|c|c|c|c|}
\hline \multirow[b]{2}{*}{ Item } & \multirow[b]{2}{*}{ Total observations } & \multirow[b]{2}{*}{ Number of studies } & \multirow[b]{2}{*}{ Rho $^{1}$} & \multicolumn{2}{|c|}{$95 \%$ Confidence interval } & \multirow[b]{2}{*}{ Sampling variance } \\
\hline & & & & Lower limit & Upper limit & \\
\hline \multicolumn{7}{|l|}{ Aged ventral surface } \\
\hline Lightness, L* & 3,957 & 8 & 0.50 & 0.48 & 0.53 & 0.0011 \\
\hline Redness, $\mathrm{a}^{*}$ & 3,957 & 8 & -0.09 & -0.12 & -0.06 & 0.0020 \\
\hline Yellowness, b* & 3,957 & 8 & 0.32 & 0.29 & 0.35 & 0.0016 \\
\hline Visual color & 4,108 & 9 & -0.38 & -0.40 & -0.35 & 0.0016 \\
\hline Visual marbling & 4,108 & 9 & 0.04 & 0.01 & 0.08 & 0.0022 \\
\hline Subjective firmness & 4,108 & 9 & -0.08 & -0.11 & -0.05 & 0.0022 \\
\hline \multicolumn{7}{|l|}{ Aged chop face } \\
\hline Lightness, L* & 4,213 & 11 & 0.44 & 0.41 & 0.46 & 0.0017 \\
\hline Redness, $\mathrm{a}^{*}$ & 4,213 & 11 & -0.05 & -0.08 & -0.02 & 0.0026 \\
\hline Yellowness, b* & 4,213 & 11 & 0.31 & 0.28 & 0.33 & 0.0021 \\
\hline Visual color & 4,108 & 9 & -0.38 & -0.40 & -0.35 & 0.0016 \\
\hline Visual marbling & 3,889 & 9 & 0.07 & 0.04 & 0.10 & 0.0023 \\
\hline Subjective firmness & 3,180 & 7 & -0.02 & -0.06 & 0.01 & 0.0022 \\
\hline \multicolumn{7}{|l|}{ Sensory estimates } \\
\hline Instrumental tenderness ${ }^{2}$ & 5,075 & 11 & -0.16 & -0.19 & -0.13 & 0.0021 \\
\hline Cook loss & 5,073 & 11 & 0.20 & 0.17 & 0.22 & 0.0020 \\
\hline Sensory tenderness & 1,556 & 7 & -0.06 & -0.11 & -0.01 & 0.0045 \\
\hline Sensory juiciness & 1,556 & 7 & -0.07 & -0.12 & -0.02 & 0.0045 \\
\hline Sensory flavor & 1,405 & 6 & 0.01 & -0.04 & 0.06 & 0.0043 \\
\hline
\end{tabular}

${ }^{1}$ Sample-weighted mean correlation.

${ }^{2}$ Includes WarnerBratzler and slice shear force evaluated chops cooked to $63{ }^{\circ} \mathrm{C}$ through $71{ }^{\circ} \mathrm{C}$. 
Table 3. Sample-weighted mean correlation coefficients of early $(1 \mathrm{~d})$ postmortem ventral loin surface instrumental redness ( $\left.\mathrm{a}^{*}\right)$ values with aged loin and chop quality parameters

\begin{tabular}{|c|c|c|c|c|c|c|}
\hline \multirow[b]{2}{*}{ Item } & \multirow[b]{2}{*}{ Total observations } & \multirow[b]{2}{*}{ Number of studies } & \multirow[b]{2}{*}{ Rho $^{1}$} & \multicolumn{2}{|c|}{$95 \%$ Confidence interval } & \multirow[b]{2}{*}{ Sampling variance } \\
\hline & & & & Lower limit & Upper limit & \\
\hline \multicolumn{7}{|l|}{ Aged ventral surface } \\
\hline Lightness, L* & 3,957 & 8 & -0.06 & -0.09 & -0.03 & 0.0020 \\
\hline Redness, a* & 3,957 & 8 & 0.49 & 0.47 & 0.52 & 0.0012 \\
\hline Yellowness, $\mathrm{b}^{*}$ & 3,957 & 8 & 0.28 & 0.26 & 0.31 & 0.0017 \\
\hline Visual color & 4,108 & 9 & 0.11 & 0.08 & 0.14 & 0.0021 \\
\hline Visual marbling & 4,108 & 9 & 0.04 & 0.01 & 0.07 & 0.0022 \\
\hline Subjective firmness & 4,108 & 9 & 0.06 & 0.03 & 0.09 & 0.0022 \\
\hline \multicolumn{7}{|l|}{ Aged chop face } \\
\hline Lightness, L* & 4,213 & 11 & -0.05 & -0.08 & -0.02 & 0.0026 \\
\hline Redness, $a^{*}$ & 4,213 & 11 & 0.46 & 0.43 & 0.48 & 0.0016 \\
\hline Yellowness, $b^{*}$ & 4,213 & 11 & 0.21 & 0.18 & 0.24 & 0.0024 \\
\hline Visual color & 3,889 & 9 & 0.09 & 0.05 & 0.12 & 0.0023 \\
\hline Visual marbling & 3,889 & 9 & 0.11 & 0.07 & 0.14 & 0.0023 \\
\hline Subjective firmness & 3,180 & 7 & 0.03 & -0.01 & 0.06 & 0.0022 \\
\hline \multicolumn{7}{|l|}{ Sensory estimates } \\
\hline Instrumental tenderness ${ }^{2}$ & 5,075 & 11 & -0.07 & -0.10 & -0.04 & 0.0021 \\
\hline Cook loss & 5,073 & 11 & 0.05 & 0.02 & 0.07 & 0.0022 \\
\hline Sensory tenderness & 1,556 & 7 & -0.07 & -0.12 & -0.02 & 0.0045 \\
\hline Sensory juiciness & 1,556 & 7 & -0.05 & -0.10 & 0.00 & 0.0045 \\
\hline Sensory flavor & 1,405 & 6 & -0.06 & -0.11 & -0.01 & 0.0043 \\
\hline
\end{tabular}

${ }^{1}$ Sample-weighted mean correlation.

${ }^{2}$ Includes Warner-Bratzler and slice shear force evaluated chops cooked to $63{ }^{\circ} \mathrm{C}$ through $71{ }^{\circ} \mathrm{C}$.

Table 4. Sample-weighted mean correlation coefficients of early $(1 \mathrm{~d})$ postmortem ventral loin surface instrumental yellowness $\left(b^{*}\right)$ values with aged loin and chop quality parameters

\begin{tabular}{|c|c|c|c|c|c|c|}
\hline \multirow[b]{2}{*}{ Item } & \multirow[b]{2}{*}{ Total observations } & \multirow[b]{2}{*}{ Number of studies } & \multirow[b]{2}{*}{ Rho $^{1}$} & \multicolumn{2}{|c|}{$95 \%$ Confidence interval } & \multirow[b]{2}{*}{ Sampling variance } \\
\hline & & & & Lower limit & Upper limit & \\
\hline \multicolumn{7}{|l|}{ Aged ventral surface } \\
\hline Lightness, L* & 3,957 & 8 & 0.37 & 0.34 & 0.40 & 0.0015 \\
\hline Redness, $a^{*}$ & 3,957 & 8 & 0.10 & 0.07 & 0.13 & 0.0020 \\
\hline Yellowness, $b^{*}$ & 3,957 & 8 & 0.33 & 0.30 & 0.36 & 0.0016 \\
\hline Visual color & 4,108 & 9 & -0.26 & -0.29 & -0.23 & 0.0019 \\
\hline Visual marbling & 4,108 & 9 & 0.04 & 0.01 & 0.07 & 0.0022 \\
\hline Subjective firmness & 4,108 & 9 & -0.03 & -0.06 & 0.00 & 0.0022 \\
\hline \multicolumn{7}{|l|}{ Aged chop face } \\
\hline Lightness, L* & 4,213 & 11 & 0.28 & 0.25 & 0.30 & 0.0022 \\
\hline Redness, $\mathrm{a}^{*}$ & 4,213 & 11 & 0.07 & 0.04 & 0.10 & 0.0026 \\
\hline Yellowness, b* & 4,213 & 11 & 0.27 & 0.24 & 0.30 & 0.0022 \\
\hline Visual color & 3,889 & 9 & -0.23 & -0.26 & -0.20 & 0.0021 \\
\hline Visual marbling & 3,889 & 9 & 0.09 & 0.06 & 0.12 & 0.0023 \\
\hline Subjective firmness & 3,180 & 7 & 0.00 & -0.04 & 0.03 & 0.0022 \\
\hline \multicolumn{7}{|l|}{ Sensory estimates } \\
\hline Instrumental tenderness ${ }^{2}$ & 5,075 & 11 & -0.17 & -0.20 & -0.15 & 0.0020 \\
\hline Cook loss & 5,073 & 11 & 0.17 & 0.14 & 0.19 & 0.0021 \\
\hline Sensory tenderness & 1,556 & 7 & -0.02 & -0.07 & 0.03 & 0.0045 \\
\hline Sensory juiciness & 1,556 & 7 & -0.02 & -0.07 & 0.03 & 0.0045 \\
\hline Sensory flavor & 1,405 & 6 & 0.00 & -0.05 & 0.05 & 0.0043 \\
\hline
\end{tabular}

${ }^{1}$ Sample-weighted mean correlation.

${ }^{2}$ Includes Warner-Bratzler and slice shear force evaluated chops cooked to $63{ }^{\circ} \mathrm{C}$ through $71{ }^{\circ} \mathrm{C}$. 
Table 5. Sample-weighted mean correlation of early (1 d) postmortem ventral loin surface visual color with aged loin and chop quality parameters

\begin{tabular}{|c|c|c|c|c|c|c|}
\hline \multirow[b]{2}{*}{ Item } & \multirow[b]{2}{*}{ Total observations } & \multirow[b]{2}{*}{ Number of studies } & \multirow[b]{2}{*}{ Rho $^{1}$} & \multicolumn{2}{|c|}{$95 \%$ Confidence interval } & \multirow[b]{2}{*}{ Sampling variance } \\
\hline & & & & Lower limit & Upper limit & \\
\hline \multicolumn{7}{|l|}{ Aged ventral surface } \\
\hline Lightness, L* & 4,110 & 8 & -0.51 & -0.53 & -0.48 & 0.0011 \\
\hline Redness, $\mathrm{a}^{*}$ & 4,110 & 8 & 0.22 & 0.19 & 0.25 & 0.0018 \\
\hline Yellowness, b* & 4,110 & 8 & -0.21 & -0.24 & -0.18 & 0.0018 \\
\hline Visual color & 4,260 & 9 & 0.50 & 0.48 & 0.52 & 0.0012 \\
\hline Visual marbling & 4,260 & 9 & 0.15 & 0.13 & 0.18 & 0.0020 \\
\hline Subjective firmness & 4,260 & 9 & 0.17 & 0.14 & 0.19 & 0.0020 \\
\hline \multicolumn{7}{|l|}{ Aged chop face } \\
\hline Lightness, $\mathrm{L}^{*}$ & 4,357 & 11 & -0.43 & -0.46 & -0.41 & 0.0017 \\
\hline Redness, a* & 4,357 & 11 & 0.21 & 0.18 & 0.24 & 0.0023 \\
\hline Yellowness, b* & 4,357 & 11 & -0.16 & -0.18 & -0.13 & 0.0024 \\
\hline Visual color & 4,042 & 9 & 0.43 & 0.41 & 0.46 & 0.0015 \\
\hline Visual marbling & 4,040 & 9 & 0.12 & 0.09 & 0.15 & 0.0022 \\
\hline Subjective firmness & 3,187 & 7 & 0.04 & 0.00 & 0.07 & 0.0022 \\
\hline \multicolumn{7}{|l|}{ Sensory estimates } \\
\hline Instrumental tenderness ${ }^{2}$ & 5,223 & 11 & -0.01 & -0.03 & 0.02 & 0.0021 \\
\hline Cook loss & 5,223 & 11 & -0.21 & -0.23 & -0.18 & 0.0019 \\
\hline Sensory tenderness & 1,552 & 7 & 0.05 & 0.00 & 0.10 & 0.0045 \\
\hline Sensory juiciness & 1,552 & 7 & 0.08 & 0.03 & 0.13 & 0.0045 \\
\hline Sensory flavor & 1,401 & 6 & 0.09 & 0.04 & 0.14 & 0.0042 \\
\hline
\end{tabular}

${ }^{1}$ Sample-weighted mean correlation.

${ }^{2}$ Includes Warner-Bratzler and slice shear force evaluated chops cooked to $63^{\circ} \mathrm{C}$ through $71{ }^{\circ} \mathrm{C}$.

ventral instrumental lightness was not strongly correlated $(|\bar{r}| \geq 0.68)$ with any instrumental color or visual color, marbling or firmness trait on the aged ventral surface of the loin or the aged but freshly cut chop face.

No instrumental or subjective color parameters were moderately $(|\bar{r}|=0.36$ to 0.67$)$ or strongly correlated $(|\bar{r}| \geq 0.68)$ with traits associated with eating experience (instrumental tenderness, cook loss, sensory tenderness, juiciness, or flavor).

Marbling/extractable lipid. Extractable lipid was moderately correlated with aged ventral marbling $(\bar{r}=0.62)$ and strongly correlated with aged visual marbling of the chop face $(\bar{r}=0.69$, Table 6$)$. Extractable lipid was not moderately or strongly correlated $(|\bar{r}| \leq 0.31)$ with any instrumental color or visual color or subjective firmness trait on the aged ventral surface of the loin or the aged but freshly cut chop face.

Early postmortem ventral visual marbling was moderately correlated with aged ventral marbling $(\bar{r}=0.63)$ and aged visual marbling of the chop face $(\bar{r}=0.56$, Table 7$)$. Early postmortem ventral visual marbling was not strongly correlated $(|\bar{r}| \geq$ 0.68 ) with any instrumental color or visual color, marbling or firmness trait on the aged ventral surface of the loin or the aged chop face.
Firmness. Early postmortem ventral firmness was not strongly $(|\bar{r}| \geq 0.68)$ or moderately $(|\bar{r}|=0.36$ to 0.67$)$ correlated with any instrumental color or visual color, visual marbling or subjective firmness trait on the aged ventral surface of the loin or the aged chop face (Table 8). Nor was early postmortem ventral firmness strongly $(|\bar{r}| \geq 0.68)$ or moderately $(|\bar{r}|=0.36$ to 0.67$)$ correlated with any traits associated with eating experience (Table 7).

Ultimate pH. Early postmortem ultimate $\mathrm{pH}$ was moderately correlated with aged ventral lightness $(\bar{r}=-0.43)$, aged ventral yellowness $(\bar{r}=-0.43)$, aged ventral visual color $(\bar{r}=0.36)$, and aged visual color of the chop face $(\bar{r}=0.36$, Table 9$)$. Ultimate $\mathrm{pH}$ was not moderately $(|\bar{r}|=0.36$ to $0.67)$ or strongly correlated $(|\bar{r}| \geq 0.68)$ to traits associated with eating experience.

\section{Predictive Ability of Early Postmortem Loin Quality Parameters on Purchasing Intent and Eating Experience}

The combination of traits usually associated with pork quality that can easily be evaluated on the fabrication line of commercial processing facilities (e.g., visual color, visual marbling, subjective firmness, and muscle $\mathrm{pH})$ was not predictive $\left(R^{2} \leq 0.13\right)$ of sensory 
Table 6. Sample-weighted mean correlation coefficients of loin extractable lipid values with aged loin and chop quality parameters

\begin{tabular}{|c|c|c|c|c|c|c|}
\hline \multirow[b]{2}{*}{ Item } & \multirow[b]{2}{*}{ Total observations } & \multirow[b]{2}{*}{ Number of studies } & \multirow[b]{2}{*}{ Rho $^{1}$} & \multicolumn{2}{|c|}{$95 \%$ Confidence interval } & \multirow[b]{2}{*}{ Sampling variance } \\
\hline & & & & Lower limit & Upper limit & \\
\hline \multicolumn{7}{|l|}{ Aged ventral surface } \\
\hline Lightness, L* & 4,097 & 8 & 0.17 & 0.14 & 0.20 & 0.0018 \\
\hline Redness, a* & 4,097 & 8 & 0.10 & 0.07 & 0.13 & 0.0019 \\
\hline Yellowness, $\mathrm{b}^{*}$ & 4,097 & 8 & 0.21 & 0.18 & 0.23 & 0.0018 \\
\hline Visual color & 4,250 & 9 & 0.01 & -0.02 & 0.04 & 0.0021 \\
\hline Visual marbling & 4,250 & 9 & 0.62 & 0.60 & 0.63 & 0.0008 \\
\hline Subjective firmness & 4,250 & 9 & 0.25 & 0.22 & 0.28 & 0.0019 \\
\hline \multicolumn{7}{|l|}{ Aged chop face } \\
\hline Lightness, L* & 3,543 & 10 & 0.15 & 0.12 & 0.18 & 0.0027 \\
\hline Redness, $a^{*}$ & 3,543 & 10 & 0.23 & 0.19 & 0.26 & 0.0025 \\
\hline Yellowness, $b^{*}$ & 3,543 & 10 & 0.31 & 0.28 & 0.34 & 0.0023 \\
\hline Visual color & 3,225 & 8 & -0.02 & -0.06 & 0.01 & 0.0025 \\
\hline Visual marbling & 3,223 & 8 & 0.69 & 0.67 & 0.71 & 0.0007 \\
\hline Subjective firmness & 2,377 & 6 & 0.14 & 0.10 & 0.18 & 0.0024 \\
\hline \multicolumn{7}{|l|}{ Sensory estimates } \\
\hline Instrumental tenderness ${ }^{2}$ & 4,407 & 10 & -0.13 & -0.16 & -0.10 & 0.0022 \\
\hline Cook loss & 4,406 & 10 & -0.07 & -0.10 & -0.04 & 0.0023 \\
\hline Sensory tenderness & 1,555 & 7 & 0.10 & 0.05 & 0.15 & 0.0044 \\
\hline Sensory juiciness & 1,555 & 7 & 0.03 & -0.02 & 0.08 & 0.0045 \\
\hline Sensory flavor & 1,401 & 6 & 0.07 & 0.02 & 0.13 & 0.0043 \\
\hline
\end{tabular}

${ }^{1}$ Sample-weighted mean correlation.

${ }^{2}$ Includes Warner-Bratzler and slice shear force evaluated chops cooked to $63{ }^{\circ} \mathrm{C}$ through $71{ }^{\circ} \mathrm{C}$.

Table 7. Sample-weighted mean correlation coefficients of early (1 d) postmortem ventral loin surface visual marbling with aged loin and chop quality parameters

\begin{tabular}{|c|c|c|c|c|c|c|}
\hline \multirow[b]{2}{*}{ Item } & \multirow[b]{2}{*}{ Total observations } & \multirow[b]{2}{*}{ Number of studies } & \multirow[b]{2}{*}{ Rho $^{1}$} & \multicolumn{2}{|c|}{$95 \%$ Confidence interval } & \multirow[b]{2}{*}{ Sampling variance } \\
\hline & & & & Lower limit & Upper limit & \\
\hline \multicolumn{7}{|l|}{ Aged ventral surface } \\
\hline Lightness, L* & 4,103 & 8 & -0.09 & -0.12 & -0.06 & 0.0019 \\
\hline Redness, $a^{*}$ & 4,103 & 8 & 0.03 & 0.00 & 0.06 & 0.0020 \\
\hline Yellowness, b* & 4,103 & 8 & -0.04 & -0.07 & -0.01 & 0.0019 \\
\hline Visual color & 4,253 & 9 & 0.21 & 0.18 & 0.24 & 0.0019 \\
\hline Visual marbling & 4,253 & 9 & 0.63 & 0.61 & 0.64 & 0.0008 \\
\hline Subjective firmness & 4,253 & 9 & 0.26 & 0.23 & 0.29 & 0.0018 \\
\hline \multicolumn{7}{|l|}{ Aged chop face } \\
\hline Lightness, L* & 4,352 & 11 & -0.08 & -0.11 & -0.05 & 0.0025 \\
\hline Redness, a* & 4,352 & 11 & 0.12 & 0.09 & 0.15 & 0.0025 \\
\hline Yellowness, b* & 4,352 & 11 & 0.06 & 0.03 & 0.09 & 0.0025 \\
\hline Visual color & 4,037 & 9 & 0.23 & 0.20 & 0.26 & 0.0020 \\
\hline Visual marbling & 4,035 & 9 & 0.56 & 0.54 & 0.58 & 0.0011 \\
\hline Subjective firmness & 3,186 & 7 & 0.12 & 0.09 & 0.16 & 0.0021 \\
\hline \multicolumn{7}{|l|}{ Sensory estimates } \\
\hline Instrumental tenderness ${ }^{2}$ & 5,216 & 11 & -0.09 & -0.11 & -0.06 & 0.0021 \\
\hline Cook loss & 5,216 & 11 & -0.14 & -0.17 & -0.11 & 0.0020 \\
\hline Sensory tenderness & 1,549 & 7 & 0.12 & 0.07 & 0.16 & 0.0044 \\
\hline Sensory juiciness & 1,549 & 7 & 0.04 & -0.01 & 0.09 & 0.0045 \\
\hline Sensory flavor & 1,398 & 6 & 0.00 & -0.06 & 0.05 & 0.0043 \\
\hline
\end{tabular}

${ }^{1}$ Sample-weighted mean correlation.

${ }^{2}$ Includes Warner-Bratzler and slice shear force evaluated chops cooked to $63^{\circ} \mathrm{C}$ through $71{ }^{\circ} \mathrm{C}$. 
Table 8. Sample-weighted mean correlation coefficients of early $(1 \mathrm{~d})$ postmortem ventral loin surface subjective firmness with aged loin and chop quality parameters

\begin{tabular}{|c|c|c|c|c|c|c|}
\hline \multirow[b]{2}{*}{ Item } & \multirow[b]{2}{*}{ Total observations } & \multirow[b]{2}{*}{ Number of studies } & \multirow[b]{2}{*}{ Rho $^{1}$} & \multicolumn{2}{|c|}{$95 \%$ Confidence interval } & \multirow[b]{2}{*}{ Sampling variance } \\
\hline & & & & Lower limit & Upper limit & \\
\hline \multicolumn{7}{|l|}{ Aged ventral surface } \\
\hline Lightness, L* & 4,107 & 8 & -0.16 & -0.19 & -0.13 & 0.0018 \\
\hline Redness, a* & 4,107 & 8 & 0.01 & -0.02 & 0.04 & 0.0020 \\
\hline Yellowness, b* & 4,107 & 8 & -0.06 & -0.09 & -0.03 & 0.0019 \\
\hline Visual color & 4,257 & 9 & 0.21 & 0.18 & 0.24 & 0.0019 \\
\hline Visual marbling & 4,257 & 9 & 0.28 & 0.25 & 0.31 & 0.0018 \\
\hline Subjective firmness & 4,257 & 9 & 0.26 & 0.23 & 0.28 & 0.0019 \\
\hline \multicolumn{7}{|l|}{ Aged chop face } \\
\hline Lightness, L* & 4,354 & 11 & -0.13 & -0.16 & -0.10 & 0.0024 \\
\hline Redness, $a^{*}$ & 4,354 & 11 & 0.04 & 0.01 & 0.07 & 0.0025 \\
\hline Yellowness, b* & 4,354 & 11 & -0.03 & 0.00 & -0.06 & 0.0025 \\
\hline Visual color & 4,039 & 9 & 0.19 & 0.16 & 0.22 & 0.0021 \\
\hline Visual marbling & 4,037 & 9 & 0.24 & 0.21 & 0.27 & 0.0020 \\
\hline Subjective firmness & 3,185 & 7 & 0.09 & 0.06 & 0.13 & 0.0022 \\
\hline \multicolumn{7}{|l|}{ Sensory estimates } \\
\hline Instrumental tenderness ${ }^{2}$ & 5,220 & 11 & -0.06 & -0.09 & -0.03 & 0.0021 \\
\hline Cook loss & 5,220 & 11 & -0.15 & -0.18 & -0.12 & 0.0020 \\
\hline Sensory tenderness & 1,552 & 7 & 0.12 & 0.07 & 0.17 & 0.0044 \\
\hline Sensory juiciness & 1,552 & 7 & 0.08 & 0.03 & 0.13 & 0.0045 \\
\hline Sensory flavor & 1,401 & 6 & 0.07 & 0.02 & 0.13 & 0.0043 \\
\hline
\end{tabular}

${ }^{1}$ Sample-weighted mean correlation.

${ }^{2}$ Includes Warner-Bratzler and slice shear force evaluated chops cooked to $63{ }^{\circ} \mathrm{C}$ through $71{ }^{\circ} \mathrm{C}$.

Table 9. Sample-weighted mean correlation coefficients of early $(1 \mathrm{~d})$ postmortem loin ultimate $\mathrm{pH}$ value with aged loin and chop quality parameters

\begin{tabular}{|c|c|c|c|c|c|c|}
\hline \multirow[b]{2}{*}{ Item } & \multirow[b]{2}{*}{ Total observations } & \multirow[b]{2}{*}{ Number of studies } & \multirow[b]{2}{*}{$\mathrm{Rho}^{1}$} & \multicolumn{2}{|c|}{$95 \%$ Confidence interval } & \multirow[b]{2}{*}{ Sampling variance } \\
\hline & & & & Lower limit & Upper limit & \\
\hline \multicolumn{7}{|l|}{ Aged ventral surface } \\
\hline Lightness, $\mathrm{L}^{*}$ & 3,739 & 8 & -0.43 & -0.45 & -0.40 & 0.0014 \\
\hline Redness, $\mathrm{a}^{*}$ & 3,739 & 8 & -0.19 & -0.23 & -0.16 & 0.0020 \\
\hline Yellowness, b* & 3,739 & 8 & -0.43 & -0.46 & -0.40 & 0.0014 \\
\hline Visual color & 3,889 & 9 & 0.36 & 0.34 & 0.39 & 0.0017 \\
\hline Visual marbling & 3,889 & 9 & 0.20 & 0.16 & 0.23 & 0.0021 \\
\hline Subjective firmness & 3,889 & 9 & 0.10 & 0.07 & 0.13 & 0.0023 \\
\hline \multicolumn{7}{|l|}{ Aged chop face } \\
\hline Lightness, L* & 4,155 & 11 & -0.35 & -0.37 & -0.32 & 0.0021 \\
\hline Redness, $a^{*}$ & 4,155 & 11 & -0.15 & -0.18 & -0.12 & 0.0025 \\
\hline Yellowness, b* & 4,155 & 11 & -0.28 & -0.31 & -0.25 & 0.0023 \\
\hline Visual color & 3,840 & 9 & 0.36 & 0.33 & 0.39 & 0.0018 \\
\hline Visual marbling & 3,838 & 9 & 0.15 & 0.12 & 0.19 & 0.0022 \\
\hline Subjective firmness & 3,095 & 7 & -0.01 & -0.05 & 0.03 & 0.0023 \\
\hline \multicolumn{7}{|l|}{ Sensory estimates } \\
\hline Instrumental tenderness ${ }^{2}$ & 4,855 & 11 & -0.05 & -0.08 & -0.02 & 0.0023 \\
\hline Cook loss & 4,855 & 11 & -0.29 & -0.32 & -0.26 & 0.0019 \\
\hline Sensory tenderness & 1,398 & 7 & 0.21 & 0.16 & 0.26 & 0.0046 \\
\hline Sensory juiciness & 1,398 & 7 & 0.12 & 0.07 & 0.17 & 0.0049 \\
\hline Sensory flavor & 1,247 & 6 & 0.05 & -0.01 & 0.10 & 0.0048 \\
\hline
\end{tabular}

'Sample-weighted mean correlation.

${ }^{2}$ Includes Warner-Bratzler and slice shear force evaluated chops cooked to $63{ }^{\circ} \mathrm{C}$ through $71^{\circ} \mathrm{C}$. 
tenderness or juiciness. The combination of color, marbling, firmness, and $\mathrm{pH}$ was moderately predictive $\left(R^{2}=0.28\right)$ of sensory flavor (Table 10$)$. On the other hand, pork quality traits that can easily be evaluated on the fabrication line of commercial processing facilities were moderately predictive of traits associated with purchasing intent (e.g., aged chop color and aged chop marbling). The combination of the color, marbling, firmness, $\mathrm{pH}$, and extractable lipid was moderately predictive of aged chop face visual color $\left(R^{2}=0.26\right)$ and aged chop face visual marbling $\left(R^{2}=0.28\right)$ when chemical extractable lipid was not included as a candidate predictor variable. Including chemical extractable lipid along with early color, marbling, firmness, and $\mathrm{pH}$ was moderately predictive $\left(R^{2}=0.52\right)$ of aged visual chop face marbling (Table 10). The discrepancy in predictive ability of aged chop marbling by including or excluding extractable lipid is likely due to the skill level of the technician evaluating visual marbling.

\section{DISCUSSION}

A meta-analysis of correlations is also referred as the validity generalization procedure (Schmidt and Hunter, 2014). It was originally developed as a means to test the notion that cognitive ability predicted job performance equally well for all persons in all situations. However, a parallel point of view existed that instead stated that the validity of employment tests was not generalizable but instead were specific to each scenario. This position was referred to as the "situational specificity hypothesis." Based on that, employment tests would need to be validated each time they were used because job tasks and environmental interactions were unique to each job. The situational specificity hypothesis was based on empirical validation studies that reported the magnitude of validity coefficients to vary among job situations. This argued that validity generalization was impossible and empirical validation was required for each specific test. In other words, a meta-analysis of correlations as a means to generalize the relationship between early postmortem quality traits and aged quality traits was not possible. Validity generalization techniques, such as the one used in this meta-analysis, were developed to test the situational specificity hypothesis. The premise behind a validity generalization technique uses results of previous studies as the sample to summarize (generalize) the true relationship represented from the original studies. Validity generalization states that the evidence for situational specificity is artefactual in nature (Schmidt and Hunter, 2014). In other words, observed differences in relationships from one study to another are the results of sampling errors and not true differences. Therefore, if the residual variance is nearly 0 after the variance due to these errors are removed, then the situational specificity hypothesis is rejected and the validity generalization is accepted. The sampling variance for each correlation in the meta-analysis is $<0.01$. Therefore, based on the recommendations of Schmidt and Hunter (2014), the results of the meta-analysis are justified and the variation due to differences in methodologies (e.g., instrumental tenderness differences) was accounted for in the analysis.

Table 10. Stepwise regression predicting traits associated with eating experience and purchasing intent (dependent variables) using noninvasive early postmortem ventral surface loin traits (independent variables)

\begin{tabular}{|c|c|c|c|c|c|c|c|c|}
\hline \multirow[b]{2}{*}{ Dependent variable (trait) } & \multirow[b]{2}{*}{$\begin{array}{l}\text { Regression } \\
\text { equation }^{1}\end{array}$} & \multirow[b]{2}{*}{ Model $\mathrm{R}^{2}$} & \multicolumn{5}{|c|}{ Independent variables-Partial $\mathrm{R}^{2}$} & \multirow[b]{2}{*}{$\begin{array}{l}\text { Model } \\
P \text {-value }\end{array}$} \\
\hline & & & $\begin{array}{l}\text { Extractable } \\
\text { lipid }\end{array}$ & $\mathrm{pH}$ & $\begin{array}{l}\text { Subjective } \\
\text { firmness }\end{array}$ & $\begin{array}{l}\text { Visual } \\
\text { color }\end{array}$ & $\begin{array}{l}\text { Visual } \\
\text { marbling }\end{array}$ & \\
\hline \multicolumn{9}{|l|}{ Eating experience } \\
\hline Tenderness & $\begin{aligned} y= & -5.61+0.37 a+2.13 b \\
& +0.29 c+0.15 d\end{aligned}$ & 0.13 & 0.07 & 0.05 & 0.02 & 0.00 & - & $<0.0001$ \\
\hline Juiciness & $\begin{aligned} y= & -0.61+0.22 a+1.20 b \\
& +0.16 c+0.16 e+0.15 d\end{aligned}$ & 0.09 & 0.05 & 0.02 & 0.01 & 0.00 & 0.01 & $<0.0001$ \\
\hline Flavor & $\begin{aligned} \mathrm{y}= & 22.00-2.70 \mathrm{~b}+1.04 \mathrm{e} \\
& -0.83 \mathrm{a}-0.99 d+0.20 \mathrm{c}\end{aligned}$ & 0.28 & 0.09 & 0.07 & 0.00 & 0.05 & 0.06 & $<0.0001$ \\
\hline \multicolumn{9}{|l|}{ Purchasing intent } \\
\hline Aged chop color & $\begin{aligned} y= & -0.67+0.34 d+0.46 b \\
& +0.07 c+0.06 e-0.04 a\end{aligned}$ & 0.26 & -0.04 & 0.46 & 0.07 & 0.34 & 0.06 & $<0.0001$ \\
\hline Aged chop marbling & $\begin{aligned} y= & -1.46+0.40 a+0.16 \mathrm{e} \\
& +0.10 \mathrm{~d}+0.29 \mathrm{~b}+0.05 \mathrm{c}\end{aligned}$ & 0.52 & 0.46 & 0.00 & 0.00 & 0.01 & 0.04 & $<0.0001$ \\
\hline Aged chop marbling ${ }^{2}$ & $\begin{aligned} \mathrm{y}= & -0.46+0.34 \mathrm{e}+0.13 \mathrm{c} \\
& +0.24 \mathrm{~b}-0.04 d\end{aligned}$ & 0.28 & - & 0.24 & 0.13 & -0.04 & 0.34 & $<0.0001$ \\
\hline
\end{tabular}

\footnotetext{
${ }^{1} \mathrm{a}=$ extractable lipid; $\mathrm{b}=$ ultimate $\mathrm{pH} ; \mathrm{c}=$ ventral firmness; $\mathrm{d}=$ ventral color; $\mathrm{e}=$ ventral marbling.

${ }^{2}$ Prediction of chop marbling without extractable lipid included as a candidate variable.
} 
Postmortem aging of pork loins has benefits for the consumer because most pork loins become more tender during a postmortem aging period (Dilger et al., 2010). This tenderization is partially due proteolysis of myofibrils and associated proteins (Koohmaraie et al., 2002). However, meat color is expected to deteriorate with postmortem aging. Meat color stability is largely a function of oxygen consumption and metmyoglobin reduction during storage (Mancini and Hunt, 2005). During postmortem aging, myoglobin oxidizes and fresh meat becomes discolored. Quantifying the differences in color from early postmortem aging times to later aging times is important as these times represent the 2 different instances where meat purveyors (early) and consumers (late) make quality observations. Due to the expected changes that occur with postmortem aging, it is important to determine whether meat purveyors and consumers are observing loins to be similar in color. Based on previous reports (Klehm et al., 2018), it was not surprising to note that based on data from the meta-analyses, ventral instrumental color changed during postmortem aging. What is important to note is that although instrumental lightness values increased (loins became lighter), the magnitude of the change was $3.99 \mathrm{~L}^{*}$ units. A change of this magnitude represents less than 1 color score difference in visual color based on NPPC visual color. The magnitude of difference between NPPC visual color scores is $6 \mathrm{~L}^{*}$ units (NPPC, 1999). In addition to becoming lighter, with postmortem aging, both $\mathrm{a}^{*}$ (redness) and $b^{*}$ yellowness increased. This increase in redness may explain why, while instrumentally loins become lighter, in terms of NPPC color score, they were perceived as "darker." Visual color scores increased during postmortem aging, but the magnitude of the difference only increased 0.21 NPPC visual color units. Although statistically significant, the magnitude of these changes suggests that meat purveyors and consumers would perceive similar loins to be similar despite the time spent in postmortem aging.

Although the change in color during postmortem aging was expected, it was not known whether this change would proceed in a predictable fashion in all loins. If all loins, regardless of initial quality traits, experienced the same pattern and magnitude of change during postmortem aging, the correlation between early and aged ventral loin traits would be expected to be high. In terms of pork quality grading systems, this would be ideal as "high quality" loins based on color observations at the time of quality evaluation in the processing facility would continue to appear, within a population, as "high quality" to a consumer. Within single traits (e.g., early ventral $\mathrm{L}^{*}$ to aged ventral $\mathrm{L}^{*}$ ), correlations were weak (firmness, $b^{*}$ ) or moderate (L*, $\mathrm{a}^{*}$, color, marbling). This suggests some similarity in the ways that these traits change with aging, but not perfect, or even strong, correlation between the 2 observation times.

Further complicating this relationship between meat purveyors and consumer evaluations of quality is the difference between the surfaces being evaluated. At early postmortem times, intact loins are observed, but consumers are more likely to observe quality on the cut surface (chop face) of loins. Therefore, the strength of the relationship between observations on the ventral surface at early times postmortem with those on the aged chop surface must be established. Again, within single traits (e.g., early ventral $\mathrm{L}^{*}$ to aged chop $\mathrm{L}^{*}$ ), correlations were weak (firmness, $\mathrm{b}^{*}$ ) or moderate ( $\mathrm{L}^{*}, \mathrm{a}^{*}$, color, marbling). This suggests that loins judged "dark" using the ventral side at early postmortem times are likely to appear "dark" to consumers after aging and when observing the chop face. Although not perfect, these correlations appear consistent enough to allow for ventral loin observations to be used at early postmortem aging times.

The emphasis on visual observations of color and marbling is important because consumers use fresh color to make purchasing decisions (Brewer et al., 1999, 2001). However, ultimate quality of a purchase is determined based on eating experience. To have utility in categorizing loins based on quality, early observations of loin quality traits should be predictive of eating experience traits like tenderness, juiciness, and flavor. However, correlations between eating experience traits and single early ventral loin quality traits are weak at best. No single correlation coefficient exceeded an absolute value of 0.17 , and many confidence intervals around these correlation coefficients contained zero. This indicates the overall weakness of these correlations. In terms of predictive ability, no combination of traits that are routinely evaluated at the processing facility during early postmortem evaluation was able to account for more than $13 \%$ of the variation in either sensory tenderness or juiciness. Using all available traits, only $28 \%$ of the variability in pork flavor was accounted for. Thus, the ability of early postmortem ventral loin observations to predict eating experience may not be reliable.

\section{CONCLUSION}

Historically, marbling has been considered important for positive eating experiences, but according to the meta-analysis, no measure of 
color or marbling would be a reliable sorting tool to determine loins that would provide a favorable or less favorable eating experience. Furthermore, the combination of pork quality traits routinely evaluated on the loin fabrication line during early postmortem evaluations is poor predictors of eating experience. Even though color changed during postmortem aging, the magnitude of change is likely not great enough to change the overall perception of the product, therefore, making color and marbling suitable parameters for sorting pork chops based on consumer purchasing preferences.

\section{LITERATURE CITED}

AMSA. 2012. AMSA meat color measurement guidelines. http://www.meatscience.org/docs/default-source/publications-resources/Hot- Topics/2012_12_meat_clr_guide. pdf?sfvrsn=0 (Accessed 20 October 2017).

Arthur, W., W. Bennett, and A. I. Huffcutt. 2001. Metaanalysis of correlations. In: W. Arthur, editor. Conducting meta-analysis using SAS. Lawrence Erlbaum Associates, Inc., Publishers, Mahwah, NJ. p. 57-116.

Brewer, M.S., and F. K. McKeith. 1999. Consumer-rated quality characteristics are related to purchase intent of fresh pork. J. Food Sci. 64:171-174. doi:10.1111/j.13652621.1999.tb09885.x

Brewer, M. S., L. G. Zhu, and F. K. McKeith. 2001. Marbling effects on quality characteristics pork loin chops: consumer purchase intent, visual and sensory characteristics. Meat Sci. 59:153-163. doi: 10.1016/S0309-1740(01)00065-1

Dilger, A. C., P. J. Rincker, J. M. Eggert, F. K. McKeith, and J. Killefer. 2010. Pork tenderness and postmortem tenderization: correlations with meat quality traits and the impact of sire line. J. Muscle Foods. 21:529-544. doi: 10.1111/j.1745-4573.2009.00201.x

Huff-Lonergan, E., T. J. Baas, M. Malek, J. C. Dekkers, K. Prusa, and M. F. Rothschild. 2002. Correlations among selected pork quality traits. J. Anim. Sci. 80:617-627. doi: $10.2527 / 2002.803617 x$

Klehm, B. J., D. A. King, A. C. Dilger, S. D. Shackelford, and D. D. Boler. 2018. Effect of packaging type during postmortem aging and degree of doneness on pork chop sensory traits of loins selected to vary in color and marbling. J. Anim. Sci. 96:1736-1744. doi:10.1093/jas/ sky084

Koohmaraie, M., M. P. Kent, S. D. Shackelford, E. Veiseth, and T. L. Wheeler. 2002. Meat tenderness and muscle growth: is there any relationship? Meat Sci. 62:345-352. doi:10.1016/S0309-1740(02)00127-4

Mancini, R. A. and M. C. Hunt. 2005. Current research in meat color. Meat Sci. 71:100-121. doi: 10.1016/j. meatsci.2005.03.003

Norman, J. L., E. P. Berg, H. Heymann, and C. L. Lorenzen. 2003. Pork loin color relative to sensory and instrumental tenderness and consumer acceptance. Meat Sci. 65:927933. doi:10.1016/S0309-1740(02)00310-8.

NPPC. 1991. Procedures to evaluate market hogs. 3rd ed. Natl. Pork Prod. Counc., Des Moines, IA.

NPPC. 1999. Official color and marbling standards. Natl. Pork Prod. Counc., Des Moines, IA.

Rosen, G. D. 2006. Holo-analysis. Poult. Sci. 85:957-959. doi:10.1093/ps/85.6.957

Sauvant, D., P. Schmidely, J. J. Daudin, and N. R. St-Pierre. 2008. Meta-analyses of experimental data in animal nutrition. Animal 2:1203-1214. doi:10.1017/ S1751731108002280.

Schmidt, F. L., J. E. Hunter. 2014. Meta-analysis of correlations corrected individually for artifacts. In: L. Barrett, editor, Methods of meta-analysis: correcting error and bias in research findings. 3rd ed. Sage publishing, Los Angeles, CA. p. 87-164.

Taylor, R. 1990. Interpretation of the correlation coefficient. A basic review. J. Diagn. Med. Sonor. 6:35-39. doi: 10.1177/875647939000600106

USDA. 2017. U.S. grade standards: pork carcasses. https://www. regulations.gov/document?D=AMS_FRDOC_0001-1640 (Accessed 16 November 2017). 